\title{
Synergistic effect of microRNA and albumin-bound nanoparticles for inhibition of glioblastoma cancer cell proliferation
}

\author{
Maria Shariatnasery $^{1,2}$, Shiva Irani ${ }^{\circledR *}$, Masoud Soleimani ${ }^{\circledR 2}$, Navid Goodarzi ${ }^{3}$, Rassoul Dinarvand ${ }^{3,4}$ \\ ${ }^{1}$ Department of Biology, Science and Research Branch, Islamic Azad University, Tehran, Iran, ${ }^{2}$ School of Medical Sciences, \\ Tarbiat Modares University, Tehran, Iran, ${ }^{3}$ Nanotechnology Research Centre, Faculty of Pharmacy, Tehran University of \\ Medical Sciences, Tehran, Iran, ${ }^{4}$ Department of Pharmaceutics, Faculty of Pharmacy, Tehran University of Medical Sciences, \\ Tehran, Iran
}

\begin{abstract}
The functional significance of upregulation miR-34a in combination with albumin-bound paclitaxel nanoparticles in U251 glioblastoma cell line has been evaluated. The MTT assay determined that miR$34 \mathrm{a}$ and albumin-bound paclitaxel nanoparticles can reduce cell viability, but the combination of both factors has a stronger effect on cell viability. The application of qRT-PCR has demonstrated that the transduction of miR-34a could lead to exogenous upregulation of miR-34a level and downregulation of SURVIVIN. Moreover, treatment of U251 cells with miR-34a and nanoparticles together considerably inhibit SURVIVIN expression compared to miR-34a and nanoparticles alone. Flow cytometry showed that upon miR-34a overexpression cell cycle arrested in G1 phase, while treatment with nanoparticles increased the cell population in G2 phase. Upregulation of miR-34a along with treatment with nanoparticles elevated the number of cells arrested in G1/ G2 phases of the cell cycle. Expression of miR-34a with albumin-bound paclitaxel nanoparticles reduced cell viability, downregulated SURVIVIN and enhanced cell cycle arrest in G1/G2 phases. Thus, the upregulation of miR-34a with these nanoparticles are potential candidates therapeutic for glioblastoma cancer.
\end{abstract}

Keywords: miR-34a. Glioblastoma. Albumin. Paclitaxel. Nanoparticles. Combination therapy.

\section{INTRODUCTION}

Glioblastoma (GBM) is the most prevalent form of brain tumor which accounted for $15.4 \%$ of all primary brain tumors and about $60-70 \%$ of all astrocytomas (Sordillo, Sordillo, Helson, 2015). Despite the fact that there has been progress in cancer therapies such as surgery, radiation and chemotherapy. Unfortunately, most of the glioma patients passed away during their course of treatments. The survival rate is quite low -less than oneyear and the five-year survival rate is near $10 \%$ of GBM patients. The treatment of GBM is difficult due to the fact that tumors composed of a mix of different kinds of cells. Hence, finding new therapies is necessary for treatment and improvement of patient lives. Like other cancers, the key signaling pathways such as RAS, tumor protein 53, phosphoinositide kinase 3 (PIK3) pathways and along with factors that control cell cycle, have been known to be

\footnotetext{
*Correspondence: S. Irani. Department of Biology, Science and Research Branch, Islamic Azad University, Tehran, Iran. Email: s.irani@srbiau.ac.ir, shi_irani@yahoo.com
}

disrupted in GBM (Appin, Brat, 2014; Palanichamy et al., 2009).

MicroRNAs (also known as miRNAs or miRs) are small non-coding RNAs, which their mature forms have 20-25 nucleotides long. miRNAs regulate more than $60 \%$ of all human protein-coding genes and constitute an important regulatory network in all cell types. They have both inducing and inhibitory function by targeting promoters and mRNAs (Rad et al., 2015). However, most of the known miRNAs are identified to have an inhibitory function by suppressing the gene expression at the posttranscriptional level.

Like other coding genes, miRNAs are also overexpressed or down-regulated in cancers. So, they are considered to be ideal candidates for cancer therapy, prognosis and even diagnosis (Fallah et al., 2015; Kouhkan et al., 2015; Mobarra et al., 2015a; Rad et al., 2013; Soufi-Zomorrod et al., 2016). One of the best well-studied miRNAs with tumor-suppressor function is miR34a. It has been shown that its expression is high in normal tissue where as its expression is suppressed in 
colon cancer (Roy et al., 2012), breast cancer (Kang et al., 2015), lung cancer (Gallardo et al., 2009), brain tumors (Guessous et al., 2010) and almost all cancer types (Chen, $\mathrm{Hu}, 2012$ ). This tumor-suppressor miR has been known to have multiple anti-tumorigenesis functions. For instance, inhibiting cell proliferation, inducing apoptosis, cell cycle arrest, reducing cell migration and reversing the chemoresistance to some drugs by targeting important oncogenes in different cancer types as well (Chen, $\mathrm{Hu}$, 2012; Li et al., 2012; Wu et al., 2014).

Paclitaxel is among the most important drug molecules used for chemotherapy in some modern treatment of different types of cancer, such as breast, melanoma, prostate, and bladder. The mechanism of paclitaxel is interfering with mitotic spindle assembly where the drug inhibits depolymerization of microtubules (Rowinsky, Donehower, 1995). Cells treated with paclitaxel undergo apoptosis or G2/M arrest. Due to some limitations in clinical application of paclitaxel, a novel formulation of paclitaxel was introduced as nanoparticles-albumin-bound (nab-Paclitaxel, ABRAXANE ${ }^{\circledR}$ ). The albumin-bound paclitaxel nanoparticles offered an alternative delivery method for improving efficacy and reducing adverse effects (Nateghian et al., 2016).

In the present study, we conducted a survey on the anti-tumorigenesis effects of ectopic expression of miR$34 \mathrm{a}$ along with albumin-bound paclitaxel nanoparticles on U251 glioblastoma cell line. U251 cells were transduced with a lentiviral vector harboring miR-34a and treated with albumin-bound paclitaxel nanoparticles. Cell viability, gene expression and cell cycle analysis carried out to determine the potential anti-cancer effect of miR-34a and albumin-bound paclitaxel nanoparticles on U251 cells.

\section{MATERIAL AND METHODS}

\section{Chemicals}

Human serum albumin (HSA) purchased from Sigma, USA. Paclitaxel supplied as the pure powder by McChem, India. Ethanol, chloroform, DMSO and other solvent were used as an analytical grade $(>98 \%)$ and purchased from Merck, Germany. Water used as double distilled water in all experiments.

\section{Cell culture}

Human glioblastoma (GBM) cell line U251 was obtained from Pasteur Institute of Iran. U251 were maintained in Dulbecco's modified Eagle's medium (DMEM) supplemented with 10\% fetal bovine serum (Gibco, USA). $100 \mu \mathrm{g} / \mathrm{mL}$ penicillin, and $100 \mu \mathrm{g} / \mathrm{mL}$ streptomycin, and incubated at $37{ }^{\circ} \mathrm{C}$ with $5 \% \mathrm{CO}_{2}$.

\section{Lentivirus Packaging}

The pLex-miR-34a plasmid and pLex plasmid (empty vector) were obtained from Stem Cell Technology Research Center, Tehran, Iran. Lentivectors were co-transfected along with packaging plasmids, psPAX2 and pMD.2G into the HEK293 T cell line using calcium-phosphate transfection as previously described (Langroudi et al., 2015). Lentiviruses were collected $48 \mathrm{~h}$ after transfection and concentrated using an ultracentrifuge (Jiang et al., 2015).

For transduction, the U251 cells were infected with $\mathrm{pLex}-\mathrm{miR}-34 \mathrm{a}$ vector or $\mathrm{pLEx}$ vector at the confluence of $60 \%$ at a multiplicity of infection (MOI) of 8 along with Polybrene $4 \mu \mathrm{g} / \mathrm{mL}$. Then, transduction efficacy was estimated by fluorescence microscopy (Manufacture, model) for GFP-positive cells.

\section{Albumin-bound paclitaxel nanoparticles preparation}

Albumin-bound paclitaxel nanoparticles were prepared by a method inspired by nab technology. Paclitaxel (100 mg) was dissolved in chloroform: ethanol $(1: 1 \mathrm{v} / \mathrm{v})$. HSA (4750.0 mg) was dissolved in WFI (17.500 mg).

Paclitaxel inorganic phase was loaded in HSA solution under probe sonicator by the amplitude of 40 , and sonication was continued for 4 min and then seized by the homogenizer. Remaining solvents were evaporated under reduced pressure by rotary evaporator for 30 minutes. Finally, the product was lyophilized for $48 \mathrm{~h}$ at $-50{ }^{\circ} \mathrm{C}$ (Christ, Alpha 2-4 LD, Germany) for further characterization. The final powder has a loading of $10 \%$.

\section{Determination zeta potential and particles size distribution}

The size and zeta potential of the nanoparticles were determined using a Zetasizer Nano ZS analyzer (Malvern Instruments, UK) with a $\mathrm{He}-\mathrm{Ne}$ laser beam at a wavelength of $633 \mathrm{~nm}$ at $25^{\circ} \mathrm{C}$ (scattering angle of $90^{\circ}$ ). Samples were diluted to appropriate concentrations with distilled/filtered water if necessary. Triplicate samples were analyzed in each case. 


\section{Morphology of nanoparticles}

The morphology of the nanoparticles was characterized by using scanning electron microscopy (SEM) (Philips XL30, The Netherlands). For SEM imaging, nanoparticles were placed on a stub, sputter coated with gold and evaluated at $30 \mathrm{kV}$ using a 6300 field emission scanning electron microscope.

\section{Cell viability assay}

Cell viability was determined by the 3-(4,5-dimethylthiazol-2-yl) -2,5-diphenyltetrazolium bromide (MTT, Sigma USA) assay. Briefly, u251 cells in $80 \%$ confluency were detached by Trypsin. $25 \%$ EDTA and they were seeded at the density of $1 \times 10^{4}$ cells per well in 96 well plates and incubated. After $24 \mathrm{~h}$ the cells were treated with Temozolomide, paclitaxel, albumin-bound Paclitaxel Nanoparticles and Plex mir-34a. MTT assay carried out at $24 \mathrm{~h}, 48 \mathrm{~h}$ and $72 \mathrm{~h}$ after treatments.

\section{Gene expression analysis}

Total RNA was extracted by using high pure RNA isolation kit (Roche, Germany) and then reverse transcribed to cDNA using random hexamers $(\beta 2 \mathrm{M}$ and Survivin), stem-loop RT specific primers (for miR-34a and SNORD47) and M-MuLV Reverse Transcriptase (Promega, USA).

Quantitative Real-time PCR for mRNAs and miR-34a was done using Quantitect SYBR Green PCR Master Mix (Takara, Japan). QRT-PCR primer sequences are listed in Table I.

TABLE I - The primer sequences for QRT-PCR

\begin{tabular}{lc}
\hline sequence & Gene \\
\hline ATG CCT GCC GTG TGA AC & $\beta \mathrm{M}(\mathrm{F})$ \\
ATC TTC AAA CCT CCA TGA TG & $\beta 2 \mathrm{M}(\mathrm{R})$ \\
AGG GTG GCA GTG TCT TAG C & miR-34a (F) \\
GAG CAG GGT CCG AGG T & miR-34a (R) \\
ATC ACT GTA AAA CCG TTC CA & Snord-47 (F) \\
GAG CAG GGT CCG AGG T & Snord-47 (R) \\
GAC CAC CGC ATC TCT ACA TTC & Survivin (F) \\
CTC CTT GAA GCA GAA GAAACA C & Survivin (R) \\
\hline
\end{tabular}

\section{Cell cycle analysis}

Cell cycle analysis carried out $48 \mathrm{hr}$ after treatment of U251 cells with nanoparticles or lentivectors. In summary, cells were detached from plates and fixed for $1 \mathrm{~h}$ in $1 \mathrm{~mL}$ of $70 \%$ methanol in PBS and then re-suspended in $1 \mathrm{mg} / \mathrm{mL}$ of Propidium Iodide (PI) (Sigma, USA) and $0.5 \mathrm{mg} / \mathrm{mL}$ RNaseA (Thermo Fisher Scientific, USA) in PBS for $30 \mathrm{~min}$ at $37^{\circ} \mathrm{C}$. Approximately $1.5 \times 104$ cells were analyzed using the FL3-A channel on a CyFlow ${ }^{\circledR}$ flow cytometer (Partec, Germany). The data were analyzed by Flow $\mathrm{Jo}^{\mathrm{TM}}$ software.

\section{RESULTS}

\section{Characterization of nanoparticles}

Nanoparticles showed Z-average particle size of about $140 \mathrm{~nm}$ with PdI of 0.2 which are the characteristics of monodisperse particles. Figure 1 shows the morphological characteristics of the albumin nanoparticles, obtained by SEM. SEM micrographs clearly show the monodispersed spherical shape of the nanoparticles with minor deformation. The particles have a zeta potential of $-25.5 \mathrm{mV}$ as a suitable value for the stability of the nanoparticles for further experiments.

\section{The effect of albumin-bound paclitaxel nanoparticles on viability of U251 cells}

U251 cells were treated with the 10 to $10^{6} \mathrm{nM}$ of free paclitaxel or nanoparticles and MTT assay was carried out $24 \mathrm{~h}, 48 \mathrm{~h}$ and $72 \mathrm{~h}$ after treatment.

As it is shown in Figure 2, albumin-bound paclitaxel nanoparticles reduced cell viability compared to the control groups. Interestingly, the effect of albuminbound paclitaxel nanoparticles on cell viability was more powerful than the free drug.

Also, for the IC50 dose the $10^{5} \mathrm{nM}$ was determined for Temozolomide and free paclitaxel and but for the nanoparticle the $10^{6} \mathrm{nM}$ is IC50.

\section{The effect of miR-34a in combination with nanoparticles on cell viability}

First, U251 cells were transduced with pLex-miR-34a or pLex lentivector and the effect of forced expression of miR-34a on cell viability was evaluated. The efficacy of transduction for both groups was more than $90 \%$ (Figure 3).

Cells underwent the MTT assay at three time-points post-transduction. The exogenous expression of miR-34a did not affect cell viability after $24 \mathrm{~h}$, but it decreased the cell viability at $48 \mathrm{~h}$ and 72 after miR-34a up-regulation (Figure 4). 
A

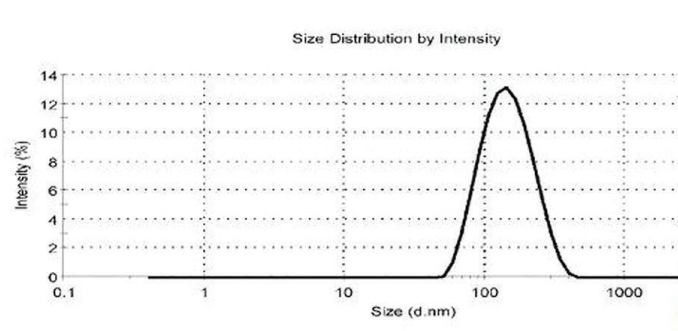

B

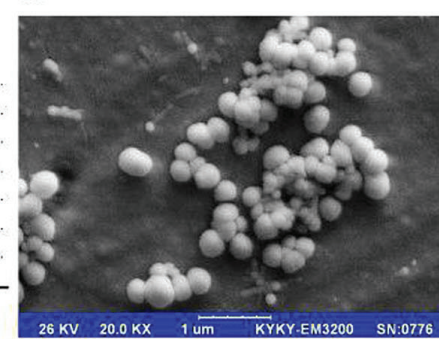

C

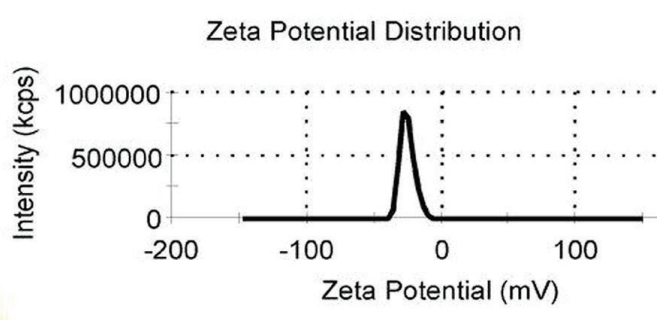

FIGURE 1 - Characterization of paclitaxel albumin-bound nanoparticles: A) Particle size distribution by intensity; B) Scanning electron microscopy (SEM) of nanoparticles. Bar indicates $1 \mu \mathrm{m}$; C) Zeta potential value of nanoparticles at $-25.5 \mathrm{mV}$.
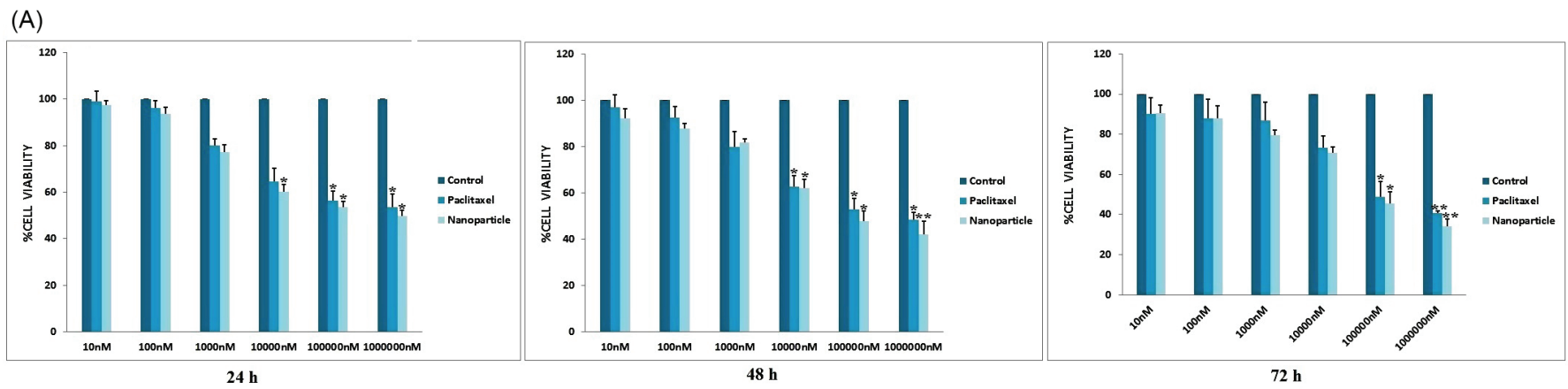

(B)

(C)
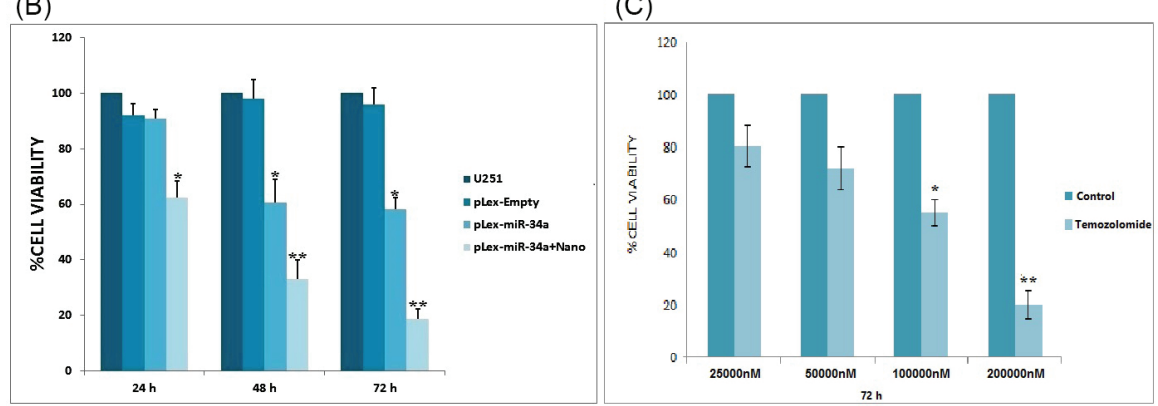

FIGURE 2 - The effect of paclitaxel and albumin-bound paclitaxel nanoparticles on cell viability of U251 cells after (A) $24 \mathrm{~h}$, (B) $48 \mathrm{~h}$ and $(\mathrm{C}) 72 \mathrm{~h}$ treatment. Data were the averages of at least three independent runs; bars, $\mathrm{SD}$. [*] $\mathrm{P}<0.05$ [**] $\mathrm{P}<0.01$.

Finally, we analyzed the effect of overexpression of miR-34a along with treatment with albumin-bound paclitaxel nanoparticles on U251 cell viability. As it is shown in Figure 4, cell viability is significantly decreased in the group treated with both factors compared with cells that only received miR-34a or control group. These results strongly suggested that overexpression of miR-34a in combination with albumin-bound paclitaxel nanoparticles can reduce the cell viability of glioblastoma cells in vitro.

\section{pLex-miR-34a overexpression in U251 cells}

Real-time PCR analysis for miR-34a was performed to find out if our pLex-miR-34a lentivector can exogenously overexpress miR-34a level in U251 cells. As Figure 5A shows, transduction of U251 cells with pLenti-miR-34a resulted in the up-regulation of the miR-34a level $(\mathrm{P}<0.05)$.
It has been shown that miR-34a as a tumorsuppressor miRNA targets a broad range of oncogenes such as BCL2, CCND1, CDK6, and CD44 (Liu et al., 2011; Sun et al., 2008; Wang et al., 2009). Eventually, for confirming that exogenous upregulation of miR-34a will result in the inhibition of its targets, the expression level of Survivin as a known direct target of miR-34a was estimated (Cao et al., 2013; Cao et al., 2014; Shen et al., 2012). Increased level of miR-34a correlated with downregulation of Survivin at mRNA level $24 \mathrm{~h}, 48 \mathrm{~h}$ and $72 \mathrm{~h}$ post-transduction $(\mathrm{P}<0.05)$ (Figure $5 \mathrm{~B})$.

It is worth mentioning that we examined the effect of the treatment of U251 cells with paclitaxel and nanoparticles on the expression of SURVIVIN Interestingly, both drugs were able to downregulate SURVIVIN expression at the mRNA level (Figure 5B) $(\mathrm{P}<0.05)$. Although the mechanism of this downregulation is unknown, the inhibitory effect of a factor on the 


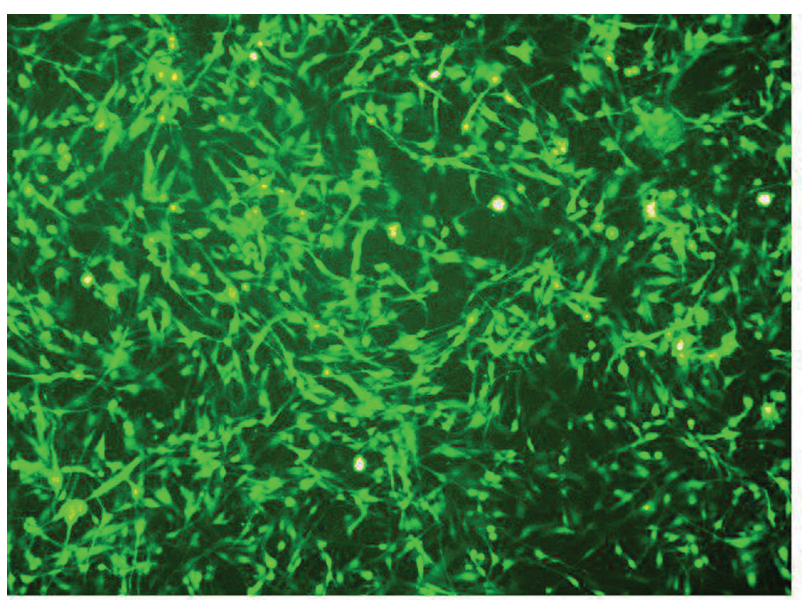

A) pLex-miR34a

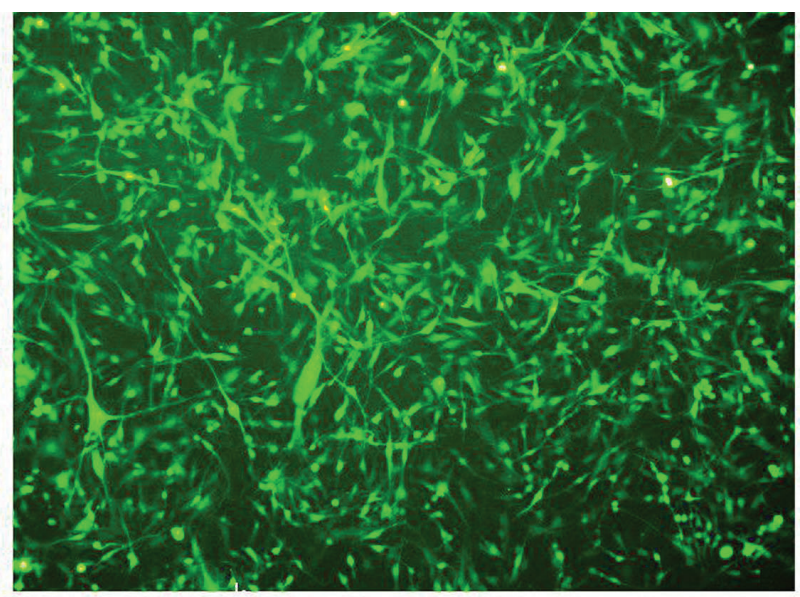

B) pLex-Empty

FIGURE 3 - Estimating the transduction efficacy of U251 cells after $48 \mathrm{~h}$ of transduced with (A) pLex-miR-34a lentivector or (B) pLex-Empty. The transduction efficacy estimated $90 \%$.

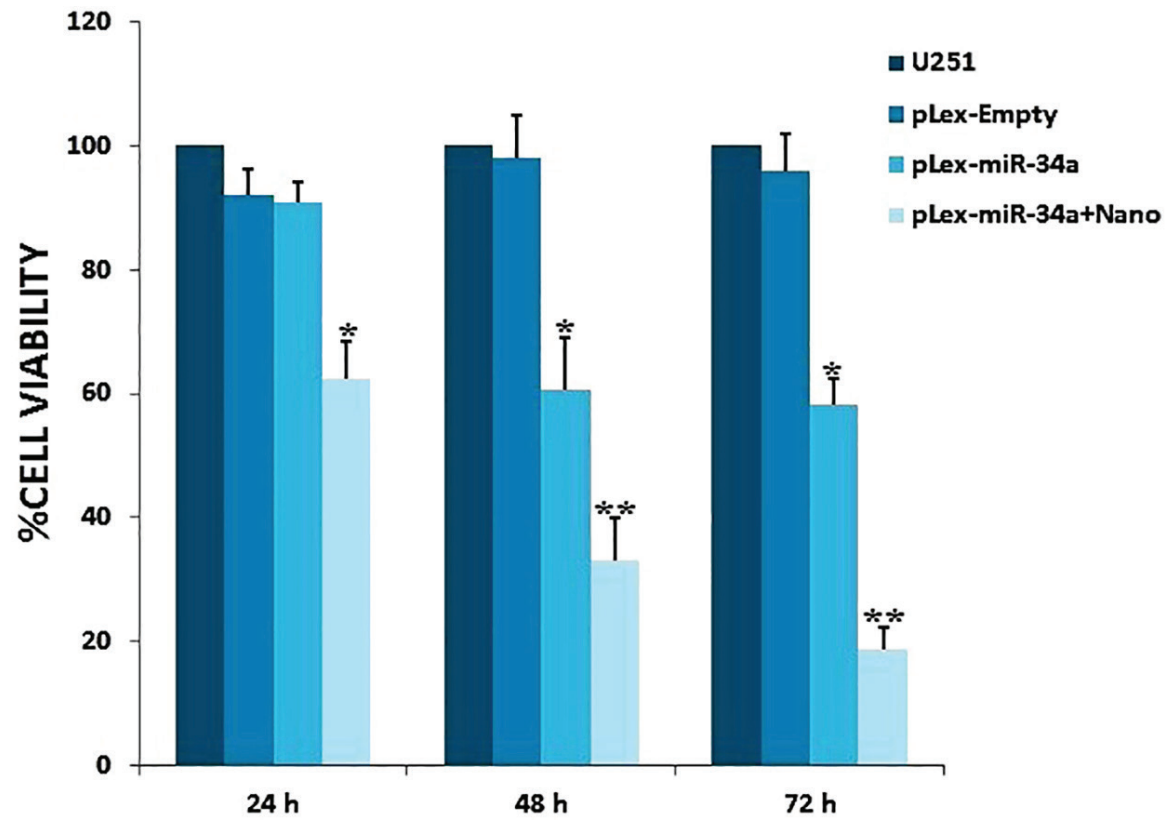

FIGURE 4 - Determination the effect of miR-34a and albumin-bound paclitaxel nanoparticles on cell viability of U251 cells after $24 \mathrm{~h}, 48 \mathrm{~h}$ and $72 \mathrm{~h}$. Data were the averages of at least three independent runs; bars, SD. [*] $\mathrm{P}<0.05$ [**] $\mathrm{P}<0.01$.

expression of an oncogene has been always known as a benefit.

\section{Cell cycle analysis of treated cells}

In order to find out the effect of miR-34a and nanoparticles on the cell cycle, the flow cytometry using PI was done. The effect of miR-34a upregulation on the cell cycle of U251 cells was in line with the previous report and arrest cell cycle at the G1 (Figure 6B). But when U251 cells were treated with nanoparticles, most of the cells were arrested in the G2 phase (Figure 6C). Moreover, treating U251 cells with the combination of miR-34a overexpression and nanoparticles showed interesting results, in most of them, cell cycle has been stopped at G1 and G2 phases of the cell cycle (Figure 6D).

\section{DISCUSSION}

MiR-34a expression is diminished in most of the human cancers, in which it counteracts tumor progression (Slabáková, Eva et al., 2017). MiR-34a belongs to the miR-34 family consisting of miR-34a, b and c. Although miR-34a derives from a polycistronic transcript, miR-34b and miR-34c share a common transcript at 11q23 loci (Lopez et al., 2018). MiR-34a is an abundant miRNA, 

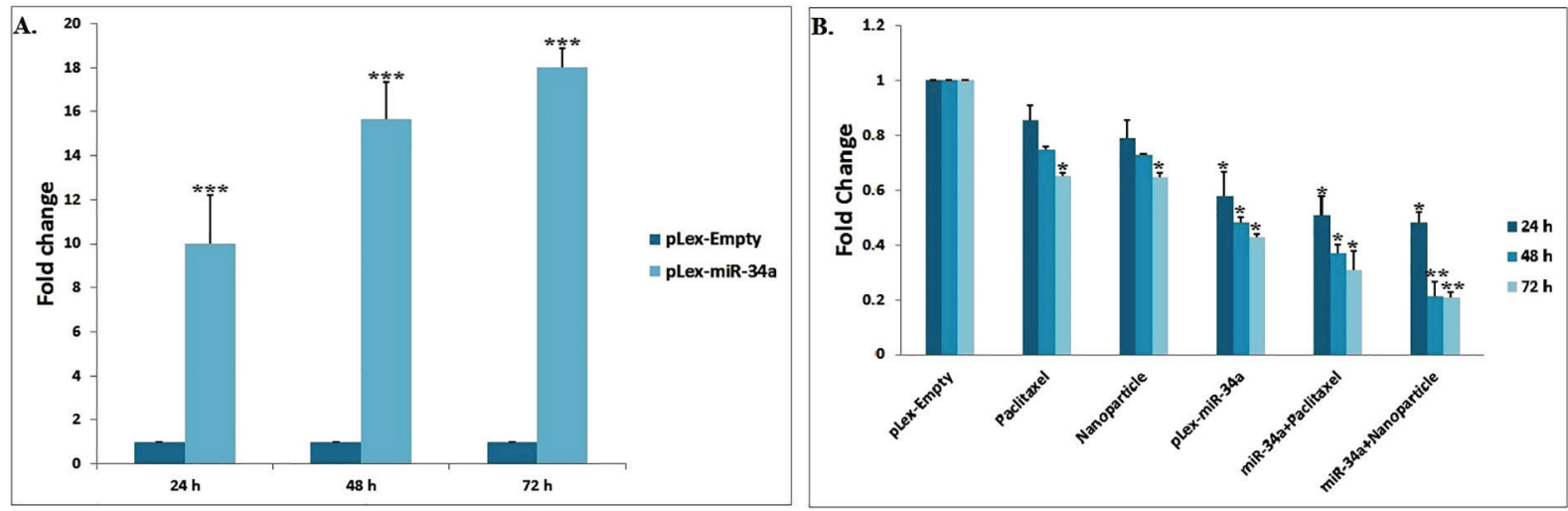

FIGURE 5 - (A) Expression level of miR-34a after $24 \mathrm{~h}, 48 \mathrm{~h}$ and $72 \mathrm{~h}$ post transduction with pLex-miR-34a compared with pLexEmpty. (B) The effect of upregulation of miR-34a, paclitaxel drug, albumin-bound paclitaxel nanoparticles and combination of both factors on Survivin expression. Data were the averages of at least three independent runs; bars, SD. [*] P $<0.05[* *], P<0.01$ and $[* * *] \mathrm{P}<0.001$.
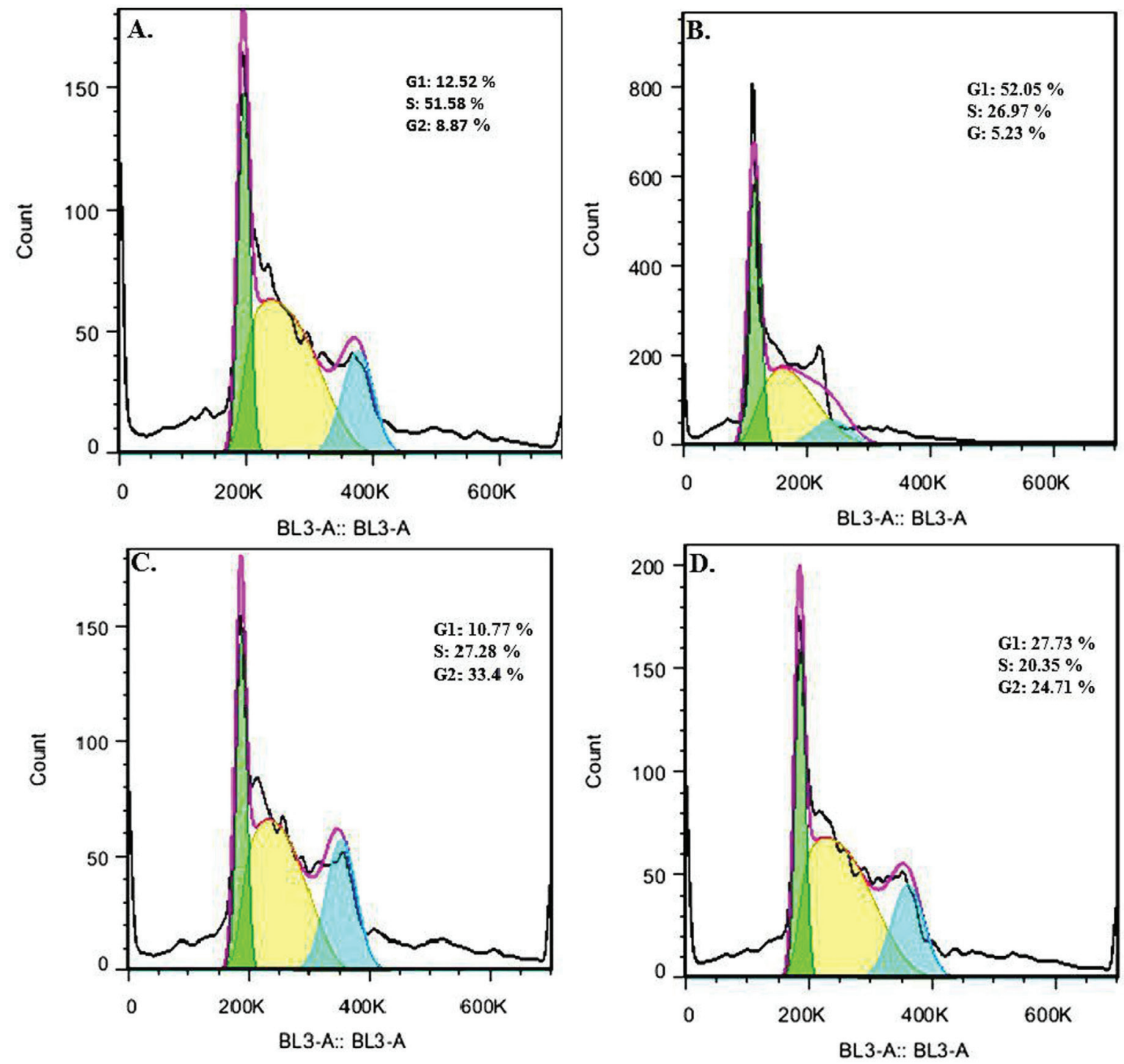

FIGURE 6 - Cell cycle assay using flow cytometry after 48 h. (A) control group (B) cells transduced with pLex-miR-34a (C) cells treated albumin-bound paclitaxel nanoparticles (D) cells that overexpressed miR-34a and treated with albumin-bound paclitaxel nanoparticles. 
ubiquitously expressed in normal human tissue, whereas $\mathrm{miR}-34 \mathrm{~b} / \mathrm{c}$ expression patterns is more tissue specific.

It has been demonstrated that miR-34a downregulation plays a vital role in cell-cycle arrest, triggering apoptosis, senescence, and inhibition of the epithelial mesenchymal transition (EMT). In addition, this miRNA is a direct target of TP53 and together they form a positive feed-forward regulatory loop. All these characters make miR-34a a promising candidate for therapeutic interventions using methods to restore its expression levels (Slabáková et al., 2017; Ito et al., 2017).

A growing body of evidence has been suggested the potential use of tumor-suppressor miRNA in combination with chemotherapies or nanoparticles as "miRNA combination therapy" in the cancer therapy field (Bader, Zhao, 2016; Mishra, Mishra, Merlino, 2016; Xie et al., 2017; Zhao et al., 2016). In the current study, we investigated the anti-cancer effect of albumin-bound paclitaxel nanoparticles along with the some forced expression of miR-34a in U251 glioblastoma cell line in vitro.

First, cell viability of U251 after overexpression of miR-34a alone or along with nanoparticle treatment was investigated. MiR-34a upregulation resulted in a reduction of cell proliferation and cell viability (Figure 4), but when it was combined with nanoparticle cell viability decreased more compared to the miR-34a-overexpressed group (Figure 4).

Then, to find out the effect of increased levels of miR-34a and nanoparticle on the expression level of miR-34a targets, the qPCR analysis was performed. MiR-34a has more than 30 target genes and one of its wellknown targets is Survivin (Geng et al., 2015). As elevated level of miR-34a was correlated with down-regulation of Survivin (Figure 5B) which is in line with the previous reports that Survivin is a direct target of miR-34a. In addition, it seems albumin-bound paclitaxel nanoparticles have an inhibitory effect on SURVIVIN expression at least at the mRNA level (Figure 5B). This is the first report on albumin-bound paclitaxel nanoparticles having another tumor suppressor effect via down-regulation of SURVIVIN in glioblastoma cells in vitro.

Finally, the effect of enhanced expression of miR-34a and albumin-bound paclitaxel nanoparticles on cell cycle was evaluated. It has been shown that miR-34a and paclitaxel have inhibitory effects on the cell cycle progression in U251 cell line. Upregulation of miR-34a resulted in cell cycle arrest in G1 whereas albumin-bound paclitaxel nanoparticles arrested the cell cycle at the G2 phase. Interestingly, a combination of both factors leads to accumulation of cells in both G1 and G2 compared to the control group (Figure 6A-C).
In summary, our results showed that forced expression of miR-34a along with albumin-bound paclitaxel nanoparticles significantly reduced cell viability,a key oncogene expression like SURVIVIN and can simultaneously arrest cell cycle at G1/G2 phases in glioblastoma cells. Although, more in vitro and in vivo studies is needed for nano- combinational therapy for improve treatment in glioblastoma. In other hand cost of nano combination is important and its seem to these treatments are more expensive than single treatment. Another factor that must be considered is viral vetors distributaion due to nature of glioblastoma.

\section{CONFLICT OF INTEREST STATEMENT}

The authors disclose any commercial associations that might create a conflict of interest in connection with submitted manuscripts.

\section{REFERENCES}

Appin CL, Brat DJ. Molecular genetics of gliomas. Cancer J. 2014;20(1):66-72.

Bader A, Zhao J. Sorafenib-microRNA combination therapy for liver cancer. Google Patents; 2016.

Cao W, Fan R, Wang L, Cheng S, Li H, Jiang J, et al. Expression and regulatory function of miRNA-34a in targeting survivin in gastric cancer cells. Tumor Biol. 2013;34(2):963-71.

Cao W, Yang W, Fan R, Li H, Jiang J, Geng M, et al. miR34 a regulates cisplatin-induce gastric cancer cell death by modulating PI3K/AKT/survivin pathway. Tumor Biol. 2014;35(2):1287-95.

Chen F, Hu SJ. Effect of microRNA-34a in cell cycle, differentiation, and apoptosis: A review. J Biochem Mol Toxicol. 2012;26(2):79-86.

Fallah P, Amirizadeh N, Poopak B, Toogeh G, Arefian E, Kohram F, Hosseini Rad SM, Kohram M, Teimori Naghadeh H, Soleimani M. Expression pattern of key micro RNA s in patients with newly diagnosed chronic myeloid leukemia in chronic phase. Int J Lab Hematol. 2015;37(4):560-8.

Gallardo E, Navarro A, Viñolas N, Marrades RM, Diaz T, Gel B, et al. miR-34a as a prognostic marker of relapse in surgically resected non-small-cell lung cancer. Carcinogenesis. 2009;30(11):1903-9. 
Guessous F, Zhang Y, Kofman A, Catania A, Li Y, Schiff D, et al. microRNA-34a is tumor suppressive in brain tumors and glioma stem cells. Cell Cycle. 2010;9(6):1031-6.

Geng D, Song X, Ning F, Song Q, Yin H. MiR-34a Inhibits viability and invasion of human papillomavirus-positive cervical cancer cells by targeting E2F3 and regulating survivin. Int J Gynecol Cancer. 2015;25(4):707-13.

Ito Y, Inoue A, Seers T, Hato Y, Igarashi A, Toyama T, Taganov KD, Boldin MP, Asahara H. Identification of targets of tumor suppressor microRNA-34a using a reporter library system. Proc Nat Acad Sci. 2017;114(15):3927-32.

Jiang W, Hua R, Wei M, Li C, Qiu Z, Yang X, Zhang C. An optimized method for high-titer lentivirus preparations without ultracentrifugation. Scientific reports. 2015;5:13875.

Kouhkan F, Mobarra N, Soufi-Zomorrod M, Keramati F, Rad SM, Fathi-Roudsari M, Tavakoli R, Hajarizadeh A, Ziaei S, Lahmi R, Hanif H. MicroRNA-129-1 acts as tumour suppressor and induces cell cycle arrest of GBM cancer cells through targeting IGF2BP3 and MAPK1. J Med Genet. 2015;53(1):2433.

Kang L, Mao J, Tao Y, Song B, Ma W, Lu Y, et al. MicroRNA-34a suppresses the breast cancer stem cell-like characteristics by downregulating Notch1 pathway. Cancer Sci. 2015;106(6):7008 .

Liu C, Kelnar K, Liu B, Chen X, Calhoun-Davis T, Li H, et al. The microRNA miR-34a inhibits prostate cancer stem cells and metastasis by directly repressing CD44. Nat Med. 2011;17(2):211-5.

Langroudi L, Jamshidi-Adegani F, Shafiee A, Rad SMAH, Keramati F, Azadmanesh K, et al. MiR-371-373 cluster acts as a tumor-suppressor-miR and promotes cell cycle arrest in unrestricted somatic stem cells. Tumor Biol. 2015;36(10):776574.

Li L, Xie X, Luo J, Liu M, Xi S, Guo J, et al. Targeted expression of miR-34a using the T-VISA system suppresses breast cancer cell growth and invasion. Mol Ther. 2012;20(12):2326-34.

Lopez CM, Peter YY, Zhang X, Yilmaz AS, London CA, Fenger JM. MiR-34a regulates the invasive capacity of canine osteosarcoma cell lines. PloS One. 2018;13(1):e0190086.
Mobarra N, Shafiee A, Rad SMAH, Tasharrofi N, Soufizomorod M, Hafizi M, et al. Overexpression of microRNA-16 declines cellular growth, proliferation and induces apoptosis in human breast cancer cells. In Vitro Cell Develop Biol Animal. 2015;51(6):604-11.

Mishra PJ, Mishra PJ, Merlino G. Integrated genomics identifies miR-32/MCL-1 pathway as a critical driver of melanomagenesis: implications for mir-replacement and combination therapy. PloS One. 2016;11(11):e0165102.

Nateghian N, Goodarzi N, Amini M, Atyabi F, Khorramizadeh MR, Dinarvand R. Biotin/folate-decorated human serum albumin nanoparticles of docetaxel: comparison of chemically conjugated nanostructures and physically loaded nanoparticles for targeting of breast cancer. Chemical Biol Drug Design. 2016;87(1):69-82.

Palanichamy K, Erkkinen M, Saia G, Chakravarti A. Molecular and genetic profiling in human gliomas. Discovery Med. 2009;7(38):75-81.

Rad SM, Langroudi L, Kouhkan F, Yazdani L, Koupaee AN, Asgharpour S, Shojaei Z, Bamdad T, Arefian E. Transcription factor decoy: a pre-transcriptional approach for gene downregulation purpose in cancer. Tumor Biol. 2015;36(7):4871-81.

Rad SMAH, Bavarsad MS, Arefian E, Jaseb K, Shahjahani M, Saki N. The role of microRNAs in stemness of cancer stem cells. Oncol Rev. 2013;7(1):e8

Rowinsky EK, Donehower RC. Paclitaxel (taxol). N Engl J Med. 1995;332(15):1004-14.

Roy S, Levi E, Majumdar AP, Sarkar FH. Expression of miR34 is lost in colon cancer which can be re-expressed by a novel agent CDF. J Hematol Oncol. 2012;5(1):58.

Shen Z, Zhan G, Ye D, Ren Y, Cheng L, Wu Z, et al. MicroRNA$34 \mathrm{a}$ affects the occurrence of laryngeal squamous cell carcinoma by targeting the antiapoptotic gene survivin. Med Oncol. 2012;29(4):2473-80.

Slabáková E, Culig Z, Remšík J, Souček K. Alternative mechanisms of miR-34a regulation in cancer. Cell Death Disease. 2017;8(10):e3100.

Sun F, Fu H, Liu Q, Tie Y, Zhu J, Xing R, et al. Downregulation of CCND 1 and CDK 6 by miR-34a induces cell cycle arrest. FEBS Letters. 2008;582(10):1564-8. 
Soufi-Zomorrod M, Hajifathali A, Kouhkan F, Mehdizadeh M, Rad SMAH, Soleimani M. MicroRNAs modulating angiogenesis: miR-129-1 and miR-133 act as angio-miR in HUVECs. Tumor Biol. 2016;37(7):9527-34.

Sordillo LA, Sordillo PP, Helson L. Curcumin for the treatment of glioblastoma. Anticancer Res. 2015;35(12):6373-8.

Wu M-Y, Fu J, Xiao X, Wu J, Wu R-C. MiR-34a regulates therapy resistance by targeting HDAC1 and HDAC7 in breast cancer. Cancer Lett. 2014;354(2):311-9.

Wang X, Liu P, Zhu H, Xu Y, Ma C, Dai X, et al. miR-34a, a microRNA up-regulated in a double transgenic mouse model of Alzheimer's disease, inhibits bcl2 translation. Brain Res Bull. 2009;80(4):268-73.
Xie Y, Murray-Stewart T, Wang Y, Yu F, Li J, Marton LJ, et al. Self-immolative nanoparticles for simultaneous delivery of microRNA and targeting of polyamine metabolism in combination cancer therapy. J Control Release. 2017;246:110-9.

Zhao J, Guerrero A, Kelnar K, Peltier HJ, Bader AG. miRNA combination therapy: In vitro anticancer synergy between miR34a mimic and next generation EGFR tyrosine kinase inhibitors (TKIs) in NSCLC. Cancer Res. 2016;76(14 Suppl):4814-4814.

Received for publication on 20 $0^{\text {th }}$ April 2018 Accepted for publication on $10^{\text {th }}$ Ocotober 2018 